\title{
AN ADENOHYPOPHYSIAL EXTRACT INFLUENCING THE OUTPUT OF SEMEN IN RABBITS, GUINEA-PIGS AND MICE
}

\author{
E. LAKOMAA AND J. E. KIHLSTRŎM \\ Institute of Zoophysiology, Uppsala, Sweden
}

(Received 6th December 1971, accepted 9th May 1972)

The release of spermatozoa in the frogs, Rana esculenta L. and $R$. pipiens Schreber, can be induced by injecting an adenohypophysial constituent (Kihlström \& Danninge, 1970) which is probably not identical with any known pituitary hormone (E. Lakomaa \& S. Renlund, unpublished data). Extracts of the pituitary of frogs (Kihlström \& Danninge, 1970), perch, rabbits, cats, cattle (Kihlström, Lakomaa \& Hall, 1971), domestic fowls and humans (E. Lakomaa, unpublished observations) have also been shown to possess such activity.

In the present study, the effect of pituitary extract was tested on the output of semen in rabbits, guinea-pigs and mice. Rabbits can easily be trained to ejaculate into an artificial vagina (Kihlström \& Melin, 1963; Melin \& Kihlström, 1963) while isolated guinea-pigs and mice ejaculate spontaneously without external stimulation, yielding plugs of coagulated semen which can be collected (Orbach, 1961).

Hypophyses were dissected from cattle in the abattoir as soon as possible after death and the glands were immediately frozen on solid carbonic acid. The adenohypophyses were carefully separated from the remaining parts of the glands and the hypophysial extract was prepared according to the method of Kihlström et al. (1971).

Seven sexually mature male rabbits of different breeds, weighing 2.9 to $4.8 \mathrm{~kg}$, were used. Injections $(2.0 \mathrm{ml})$ were given three times a week into the marginal ear vein. Thirty seconds after the injection, the artificial vagina was presented to the animal over a period of $30 \mathrm{~min}$, during which the buck was allowed to ejaculate without restraint (exhaustion test). The time between the presentation of the vagina and the first ejaculation (the reaction time) was measured with an electric stop-watch. Each ejaculate was collected separately in a small calibrated test tube to determine the volume yielded.

The number of spermatozoa was determined according to Kihlström \& Fjellström (1967), using an electric cell-counter (Celloscope 202, Lars Ljungberg \& Co. Ltd, Stockholm).

Each animal was given a total of ten injections with physiological saline and the same number of experimental injections (one of the animals received only five experimental injections). Thus, all animals served as their own controls. 

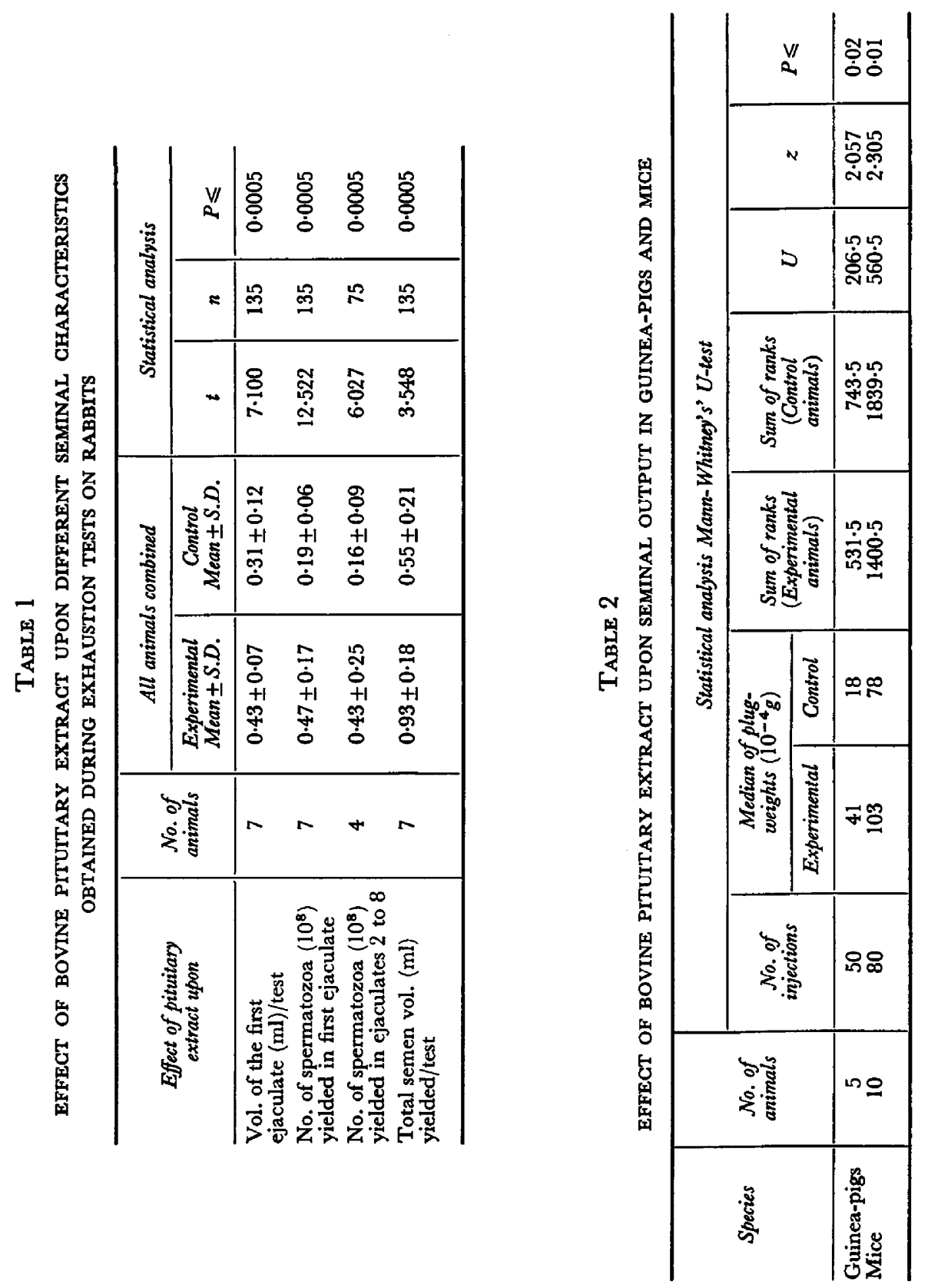
The amount of pituitary extract injected varied from 1 to 3 pituitary equivalents per injection.

The data were analysed, using Student's $t$ test. As seen from Table 1 (combined data from all animals), the volume of the first ejaculate in each exhaustion test, the number of spermatozoa in the first ejaculate and the total volume of semen yielded over the test period increased significantly following injection of the pituitary extract. When individual data were examined, the same results were obtained in five out of seven animals.

In four of the animals, the number of spermatozoa in the pooled ejaculates (Nos 2 to 8 in the exhaustion tests) was also studied and was found to increase significantly in three out of four animals. (In Table 1, the data for all four animals have been combined).

Five 6-month-old male guinea-pigs of mixed breeds and ten $2 \frac{1}{2}$-month-old male NMRI-mice were prevented from grooming their penes by a girdle, made of double-layered cotton fabric or leather, round the anterior part of the body. Ventrally, the girdles were reinforced with a firm band of steel. The animals were caged separately and a plastic tray was placed under the net floor of each cage. The seminal plugs were collected from this tray $30 \mathrm{hr}$ after each injection and dried over silica-gel to constant weight. As the plugs varied considerably in size, the total weight of the plugs collected after each injection was taken as the most suitable measure of the activity of the sexual organs.

The guinea-pigs were given injections into an ear vein every 2 nd day. Each animal received a total of ten injections $(0.2 \mathrm{ml} /$ injection). Five control injections with physiological saline were given alternately with five injections of a saline solution containing 5 pituitary-equivalents of the extract per $\mathrm{ml}$. In this way, the animals served as their own controls.

For technical reasons, the mice were distributed into two groups, each group consisting of five animals where one group served as a control group and the other as an experimental group.

Injections were given intraperitoneally every 2 nd day. Each animal received a total of eight injections $(0.1 \mathrm{ml} /$ injection). The control animals were given physiological saline, the experimental animals a saline solution containing 10 pituitary-equivalents of the pituitary extract per ml.

The data were analysed, using the non-parametric U-test (Mann \& Whitney, 1947; Siegel, 1956). The value of $U$ in this test is given by the number of times that a score in one group precedes a score in the other, when all scores are ranked according to size.

As seen from Table 2, the total weight of the plugs yielded increased significantly in both guinea-pigs and mice after injections with the pituitary extract.

This study shows that the active principle of the bovine hypophysial extract increases the output of seminal fluid as well as of spermatozoa in rabbits, and increases the weight of the seminal plugs in guinea-pigs and mice. By contrast, injections of either serum- or chronic gonadotrophin (Gestyl and Pregnyl, Pharmacia Ltd) have no effect on the numbers of spermatozoa in the ejaculates of rabbits (E. Lakomaa \& S. Renlund, unpublished data) in spite of the fact that these hormones cause a release of spermatozoa when they are injected into frogs (Frazer, 1956). 


\section{REFERENCES}

FRAZER, J. D. F. (1956) The sperm-shedding response of male toads and tree-frogs after the injection of two types of gonadotrophin. Br. J. Pharmacol. 11, 248.

Kinlström, J. E. \& Danninge, I. (1970) Release of sperm cells in the frog, Rana esculenta L., induced by a pituitary extract, probably without gonadotrophic activity. Gen. $\mathcal{E}_{\text {compar. Endocr. 14, } 592 .}$

Kinlström, J. E. \& FJeLLSTröm, D. (1967) Automatic counting of spermatozoa in rabbit semen. 7. Reprod. Fert. 14, 155.

Kinlström, J. E., LAKomaA, E. \& HALL, H. (1971) A probably non-gonadotrophic sperm-releasing activity in the pituitary gland from mammals, amphibians and fishes. Gen. $\mathscr{E}$ compar. Endocr. 17,573 .

Kinlströм, J. E. \& MeLin, P. (1963) The influence of oxytocin upon some seminal characteristics in the rabbit. Acta physiol. scand. 59, 363.

MANN, H. B. \& WhITNEY, D. R. (1947) On a test whether one of two random variables is stochastically larger than the other. Ann. math. Statist. 18, 50.

Melin, P. \& Kinlström, J. E. (1963) Influence of oxytocin on sexual behaviour in male rabbits. Endocrinology, 73, 433.

Orbach, J. (1961) Spontaneous ejaculation in the rat. Science, N.X. 134, 1072.

Siegel, S. (1956) Non-parametric statistics for the behavioral sciences. McGraw-Hill, New York. 